\title{
Scaling the influence of topographic heterogeneity on intertidal benthic communities: alternate trajectories mediated by hydrodynamics and shading
}

\author{
Frédéric Guichard ${ }^{1, *}$, Edwin Bourget ${ }^{1}$, Jean-Loup Robert ${ }^{2}$ \\ ${ }^{1}$ GIROQ, Département de Biologie and \\ ${ }^{2}$ GIREF, Département de génie civil, Université Laval, Québec, Québec G1K 7P4, Canada
}

\begin{abstract}
Scale-dependent influence of environmental complexity has become a central issue in ecology. We quantified the impact of artificial reefs on community characteristics (biomass, density) and on individual mussel growth, and we tested the relative importance of physical processes (i.e. flow velocity, substratum temperature) as intermediate factors mediating the scale-dependent influence of topographic heterogeneity on benthic communities. Twelve concrete reefs (cylinders) of 3 different sizes $(52,76$ and $115 \mathrm{~cm}$ ) were placed on randomly selected sites along a rocky intertidal platform. The area around each reef and 4 control sites were divided into 24 sampling cells $(6$ orientation and 4 distance categories). Hydrodynamic patterns around reefs and control sites were determined using the dissolution of plaster cylinders. Flow velocity was simulated around reefs using a finite-element hydrodynamic model. Substratum temperature was also measured. The biomass and density of benthic community adjacent to the reefs was sampled using $10 \times 10 \mathrm{~cm}$ quadrats before and $1 \mathrm{yr}$ after installation. Growth of individual Mytilus edulis attached to experimental panels was measured. A flow index revealed a strong scale-dependent gradient of decreasing water motion intensity with distance from the reefs, and the hydrodynamic model showed a reduction of flow velocity on the downstream side of large reefs. Substratum temperature was lower closer to reefs, and shaded areas increased with reef size. Maximum M. edulis biomass was around large reefs, while the biomasses of other dominant species were not positively influenced by reef size. Biomass and density patterns close to the reefs were significant only around large reefs, with the downstream side having the lowest $M$. edulis biomass. Growth of $M$. edulis decreased significantly with distance away from the reefs. Biomass patterns were best explained by the flow velocity around the large reefs $\left(\mathrm{R}^{2}=\right.$ 0.27 ), while mussel growth was best correlated with substratum temperature close to the medium reefs $\left(R^{2}=0.66\right)$. Our study shows that the spatial structure of the benthic community studied and its scaling with topographic heterogeneity depends on dominant mediating physical factors (i.e. hydrodynamic processes or substratum temperature).
\end{abstract}

KEY WORDS: Benthic community $\cdot$ Spatial scale $\cdot$ Intertidal $\cdot$ Environmental complexity $\cdot$ Finite element model

\section{INTRODUCTION}

A central issue in ecology is spatio-temporal scaling of community structure and dynamics (Wiens 1989,

\footnotetext{
${ }^{*}$ Present address: Department of Ecology and Evolutionary Biology, Princeton University, Princeton, New Jersey 08544, USA.E-mail: guichard@princeton.edu
}

Levin et al. 1997). The goal of spatial ecology is to determine how space and spatial scales influence population and community dynamics (Tilman \& Kareiva 1997). Theoretical studies have suggested that internal (biotic) properties of individuals and populations interact to produce spatio-temporal complexity in homogeneous environments (Deutschman et al. 1993, Bascompte \& Solé 1995). Potentially, environmental 
complexity interacts with biotic processes and influences spatial patterns (Roughgarden 1974, McLaughlin \& Roughgarden 1992, Pascual \& Caswell 1997). In marine ecosystems, many empirical studies have determined correlation scales between environmental and biological patterns (Seuront et al. 1996, Archambault et al. 1998, Legendre et al. 1997, Schneider et al. 1997, Blanchard \& Bourget 1999), but few have quantified scale-dependent processes and determined scaling rules to link environmental complexity to spatial structure in benthic communities. We experimentally quantified scale-dependent influences of meter-scale topographic heterogeneity on biomass, density and spatial structure in benthic communities. We have defined the relative importance of physical (flow velocity, substratum temperature) and biological (growth, aggregation) processes involved in a cascade of events leading to spatial structure.

Topography, measured by substratum elevation above the zero level, describes landscapes at any given point in space. Topography influences community structure in intertidal habitats by creating desiccation stress gradients (Norton 1974) and in terrestrial ecosystems by temperature and precipitation gradients (Bartha et al. 1995, Hofer et al. 1999). Topographic heterogeneity, the scale-dependent measure of topographic variability, also provides refuges against harsh physical (wind blow-down [Boose et al. 1994], fire disturbance [Takaoka \& Sasa 1996], desiccation [Garrity 1984], ice scouring [Bergeron \& Bourget 1986]) and biotic (competition and predation [Wethey \& Walters 1986, Gosselin \& Bourget 1989]) conditions. In marine ecosystems different ecological processes have been linked to topographic heterogeneity over a wide range of spatial scales from micron (Bourget 1988, Le Tourneux \& Bourget 1988, Thompson et al. 1996) to kilometer (Wolanski \& Hammer 1988, Archambault \& Bourget 1996) scales. In intertidal rocky shores, topography can influence the spatial structure of environmental variables, which in turn affect biological processes during both low and high tidal periods. Through the measurement of height above zero level, topography can be linked to the immersion period and desiccation stress. Topographic heterogeneity results in specific hydrodynamic patterns during high tide and shading and air flow patterns during low tide. At the meter scale, topographic heterogeneity from boulders has a scale-dependent influence on hydrodynamic patterns and benthic fish recruitment (Breitburg et al. 1995), as well as soft-bottom (Cusson \& Bourget 1997) and rocky-bottom (Guichard \& Bourget 1998) intertidal communities.

Mussel aggregation influences food depletion and growth of individuals. Mussels within mussel beds have lower growth rates than solitary individuals
(Okamura 1986, Svane \& Ompi 1993). Aggregated mussels also have lower body temperatures than solitary individuals during emersion (Helmuth 1998), thus suggesting that aggregation affects desiccation stress during low tide. By driving both flow velocity and shading patterns, topographic heterogeneity could therefore interact with density-dependent physical processes that influence mussels. Scaling the influence of topographic heterogeneity on benthic communities would depend on the dominant mediating factors (i.e. shading or hydrodynamics) involved in this cascade of events.

We experimentally manipulated topographic scales by adding topographic heterogeneity by way of different-sized concrete cylinder reefs in order to measure scale-dependent patterns of flow velocity, substratum temperature, abundance (biomass and density) and of Mytilus edulis growth. We more precisely tested the following hypotheses: (1) Reef size influences the change in dominant species biomass between sampling years. Reef size and position around reefs influence (2) hydrodynamics (flow velocity and water motion index), (3) substratum temperature, (4) the biomass and density of dominant species, and (5) $M$. edulis shell and mass growth. We also explored how the relative importance of hydrodynamics and shading as mediating factors explaining the influence of reefs on biological patterns changes with reef size. Our results support most of these hypotheses and establish further evidence of the scaling of biological responses to environmental heterogeneity found in intertidal ecosystems.

\section{METHODS}

Study area. A $1 \mathrm{~km}$ stretch of shore along the south shore of the St. Lawrence Estuary, Sainte-Flavie, Québec, Canada (Fig. 1), was chosen as a study site. The site met 2 major criteria: First, it was located along a relatively straight section of the coastline with no large-scale topographic features such as headlands or bays that would affect the hydrodynamic flow regime. Second, the shore, which was a rocky platform, was weakly inclined, and complex hydrodynamic patterns were less likely to develop. Overall, the Estuary shoreline was oriented along the $240^{\circ} / 60^{\circ}$ axis relative to magnetic north. The macrobenthic community was dominated by Mytilus spp. and Fucus spp. In the Estuary $M$. trossulus and $M$. edulis (hereafter Mytilus) are morphologically similar, and the newly settled fucoid species are small and difficult to distinguish to the species level. Littorina saxatilis and Littorina obtusata are also abundant (Guichard \& Bourget 1998). No known predators of the mussel have been observed in 


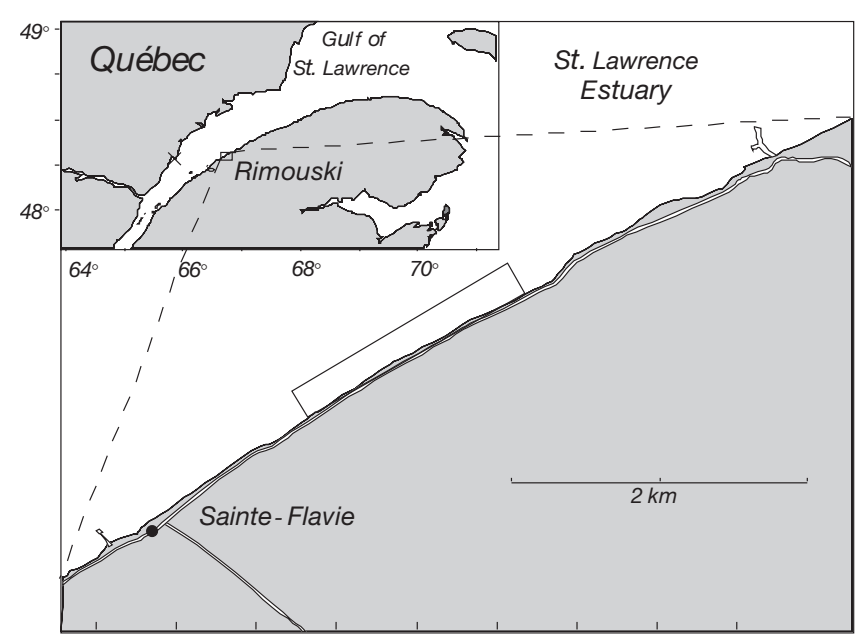

Fig. 1. Study area along the south shore of the St. Lawrence Estuary, Québec, Canada

the mid-intertidal zone of this sub-arctic area. The semi-diurnal tide ranges from about 2 (neap tides) to $4.5 \mathrm{~m}$ (spring tides). In spring, ice scouring is an important disturbance factor, and it dislodges most exposed organisms (Archambault \& Bourget 1983, Bergeron \& Bourget 1986).

Artificial reefs. The experimental design used 12 cylinder-shaped artificial reefs made from reinforced silicium-added concrete which could resist salt water dissolution. The 12 included 4 of each of 3 sizes of cylinders with equal height and diameter: small cylinders were $52 \mathrm{~cm}$, medium cylinders were $76 \mathrm{~cm}$ and large cylinders were $115 \mathrm{~cm}$. We preselected thirty $5 \times$ $5 \mathrm{~m}$ potential sites in 1994. These sites were free from topographic irregularities such as boulders and crevices larger than $20 \mathrm{~cm}$, and at least $60 \%$ of the total area was free from sediments thicker than $2 \mathrm{~cm}$, and from tide pools $>2 \mathrm{~cm}$ deep. Sixteen of the suitable preselected sites were randomly assigned as either 1 of 4 control sites or a site where 1 of the 12 (3 sizes, 4 replicates) cylinders would be placed. These cylinders (artificial reefs) were installed on 29 June 1994. As we aimed to test the influence of reefs on benthic community development over the growing season, ice scour was allowed. Ice lifts and transports erratic boulders along the shore (Drapeau 1990). During winter the unattached reefs were displaced by ice and the benthic community, unprotected by the reefs, was disturbed by ice. Since sites were selected to be completely exposed, ice disturbance was maximum, removing most exposed organisms. Reefs were reinstalled at their earlier position in April 1995 and not further displaced by wave action. At selected sites 24 sampling cells were assigned by dividing the area around the cylinders into six $60^{\circ}$ sectors relative to magnetic north and 4 dis- tance classes from the cylinders (0-40, 40-80, 80-120 and $120-160 \mathrm{~cm})$. At the control sites we structured the sampling around a medium-size circle $(76 \mathrm{~cm})$ and obtained the same number of sampling cells.

Flow measurement. Dissolution of plaster cylinders: Plaster cylinders were anchored in the center of each sampling cell (24 cells site ${ }^{-1} ; \mathrm{n}=384$; Fig. 2 ) over $24 \mathrm{~h}$ ( 2 full semi-diurnal tidal cycles), which gave a relative measure of flow velocity. Plaster mass loss is linearly related to mean water velocity (Komatsu \& Kawai 1992) and has been used previously at our study site (Guichard \& Bourget 1998). The plaster cylinders $(8 \mathrm{~cm}$ long $\times 2.5 \mathrm{~cm}$ diam.) were made from plaster of Paris (Lepage $^{\mathrm{TM}}$, Brompton, Ontario, Canada). The ends were covered with epoxy, which prevents dissolution; this means that a near-constant area was exposed during the immersion period. Before installing, the cylinders were dried for $21 \mathrm{~d}$ at room temperature and then weighed. After retrieval they were again dried for $21 \mathrm{~d}$ and reweighed $( \pm 0.005 \mathrm{~g})$. The plaster cylinders were immersed on 15 August 1995. They were kept in place $2 \mathrm{~cm}$ above the substratum by threading metal rods through them. These rods were firmly anchored into the intertidal bedrock. Dry mass loss (initial-end weight) was used as a relative index of hydrodynamic parameters (flow velocity and/or turbulence intensity).

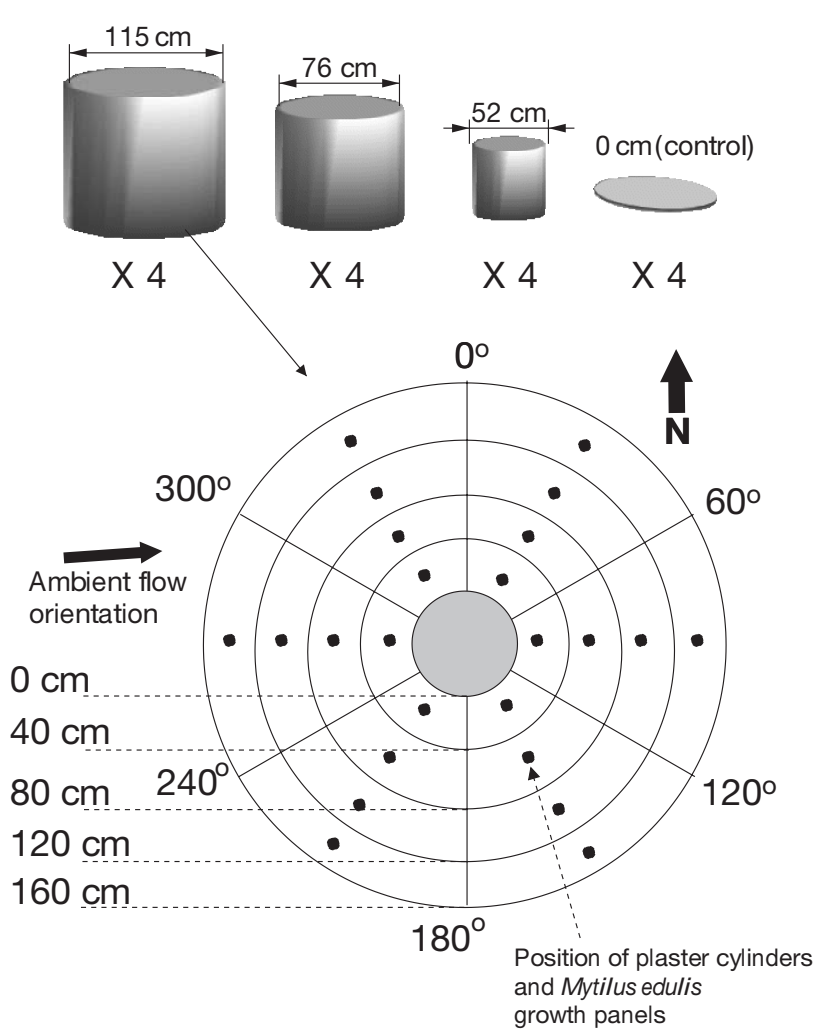

Fig. 2. Schematic of the sampling design 
Current velocity measurements: The flow at the scale of the study area was measured using 1 S4 current meter moored at $30 \mathrm{~cm}$ from the bottom at one end of the $1 \mathrm{~km}$ long study area, and 2 Marsh-McBirney electromagnetic current meters (one at $10 \mathrm{~cm}$ and the other at $60 \mathrm{~cm}$ from the bottom) moored at the other end of the study area. The current meters were moored from 14 July to 11 August 1995. Dataloggers recorded the average of 60 velocity measurements for the Marsh-McBirney meters and the average of 120 velocity measurements measured over 1 min by each probe, at 10 min intervals, when water depth was greater than $50 \mathrm{~cm}$.

Finite-element hydrodynamic model: Flow around cylinders on an intertidal inclined platform was simulated using a 2D finite-element hydrodynamic model. The model consisted of building three $200 \times 300 \mathrm{~m}$ grids each corresponding to an inclined and regular intertidal platform that included a cylinder at its center. The cylinder size was set to equal one of our artificial reefs $(52,76$ or $115 \mathrm{~cm})$. Grids were defined by triangular elements. On each element, the 2 horizontal vectors of flow velocity and water level were computed at 6 nodes (corners and center of each side of the element) at each time step (1 min). The model uses 2D (3D integrated over the water column) Navier-Stokes equations for incompressible flows (Robert \& Hamedi 1995, Robert et al. 1998). The equations express momentum conservation, mass conservation, and boundary conditions for flow velocity and water level, and the solution of the non-linear system was approximated using the Newton-Raphson variational approximation method (Hadji \& Dhatt 1997). While building the grid, elements had variable sizes, and spatial resolution increased near the cylinder up to half the cylinder size. We ran the simulation over 1 tidal cycle for each cylinder size and retained output from one time step where ambient flow velocity matched current meter data $\left(0.05 \mathrm{~m} \mathrm{~s}^{-1}\right)$. Flow orientation was then adjusted to also match current meter data. We resampled simulation data according to our experimental design (Fig. 2) to obtain mean flow velocity in each experimental sampling cell.

The model does not incorporate wind effect or wave action and reflects current meter data for water depth $>0.5 \mathrm{~m}$, as opposed to the plaster cylinders which were immersed for 2 tidal cycles and submitted to wave action in shallow water.

Substratum temperature. An infrared surface thermometer (Everest Interscience, Fullerton, CA, USA) was used to measure bare rock substratum temperature $\left( \pm 0.1^{\circ} \mathrm{C}\right)$ in the center of each sampling cell at 1 randomly selected cylinder of each size and 1 control site. The substratum and the probe were not exposed to the sun during measurements. The temperature was measured 6 times between 25 and 30 August 1997, at the end of low tide during the day. The time of low tide varied from 07:55 to 19:40 $\mathrm{h}$ meaning that the data integrated changes in position of the sun. Throughout the sampling period, ambient air temperature was near the average growing season temperature, with daily maxima between 16 and $22^{\circ} \mathrm{C}$.

Community characteristics. The benthic community was sampled 2 times at each experimental site: the first one between 5 and 20 July 1994 just after the artificial reefs were installed, and the second time the next year, between 17 July and 13 August 1995. The sampling periods were as short as possible to minimize temporal change bias.

In the 1994 samples, one $10 \times 10 \mathrm{~cm}$ quadrat was positioned using random polar coordinates in each sampling cell at each experimental site, except for cells in the $80-120 \mathrm{~cm}$ distance category $(\mathrm{n}=288)$. All nonencrusting organisms (invertebrates and algae) were removed from each quadrat. The encrusting species could not be efficiently collected but the percentage cover was visually estimated. Samples were kept frozen at $-18^{\circ} \mathrm{C}$ until analysis. In the laboratory the samples were sieved using $1 \mathrm{~mm}$ mesh sieves and all sessile or sedentary individuals were sorted and identified to either the species, or the lowest taxonomic level possible. All organisms were counted and the blotted mass of all species in each quadrat was measured using a Mettler 360 balance $( \pm 0.005 \mathrm{~g})$.

In 1995, we followed a modified sampling procedure. Specifically we sampled 4 quadrats in each sampling cell of all distance categories ( $N=1101$ due to loss of data). Random coordinates which overlapped 1994 quadrat positions were excluded. To test the influence of artificial reefs on body size structure in benthic species, we randomly selected 1 quadrat within each sampling cell of the 60 to $120^{\circ}$ category and the opposite 240 to $300^{\circ}$ category. The $80-120 \mathrm{~cm}$ distance category was excluded. Selected samples were sieved using 3 successive mesh size $(1,2$ and $8 \mathrm{~mm})$ and the number of individuals and blotted mass of each species were determined for 3 body size categories $(1-2,2-8$ and $>8 \mathrm{~mm}$ ) in each quadrat. The orientation categories chosen for the body size structure analysis were based on flow velocity which is oriented along the $270^{\circ} / 90^{\circ}$ axis at the study site (Guichard \& Bourget 1998).

Mytilus growth. The growth rate of Mytilus around artificial reefs was determined by anchoring 4 mussels on a $10 \times 10 \mathrm{~cm}$ Vexar panel in the center of each sampling cell, except for the $100 \mathrm{~cm}$ distance $(\mathrm{n}=288)$. Mussels (17 to $20 \mathrm{~mm}$ length) were selected from an intertidal site $3 \mathrm{~km}$ from our study site. Initial shell length $( \pm 0.1 \mathrm{~mm})$ and blotted mass $( \pm 0.005 \mathrm{~g})$ were recorded. One mussel valve was glued using epoxy to a corner of a Vexar panel. The panels were placed 
through metal rods anchored onto the rock bottom as for plaster cylinders. The mussels were set out between 5 June and 21 August 1995. At the end of the experiment the mussels were remeasured for changes in length and blotted mass $(\mathrm{N}=1033$ after mortality and loss of individuals from growth panels).

Data analysis. The first null hypothesis tested was that reef size would not affect the changes in dominant group (i.e. Mytilus, Fucus sp., Littorina obtusata and L. saxatilis) biomass between years. The hypothesis was tested using a mixed factorial ANOVA model (see Tables 3 \& 4) and analysed using the SAS statistical package (SAS Institute 1988). We compared the changes between the means of the 1995 samples from each cell and the corresponding quadrat sampled in 1994. The model included among-boulder variability [reef(reef size)] as the error term which tested reef size effect. The same ANOVA model was used for abundance data of dominant species sampled in 1995 (see 'Community characteristics').

Other null hypotheses tested were that reef size, orientation and distance would not affect plaster cylinder dry mass loss, Mytilus shell and mass growth or the biomass of dominant species. A mixed factorial ANOVA model (see Tables 1, 5, 6 \& 7) that included among reef variability [reef(reef size)] as an error term which tested reef size effect, and within reef variability [orientation $\times$ distance $\times$ reef(reef size)] which tested the effect of other main treatments. Residuals were visually examined, and square root transformations were applied to Mytilus biomass and growth (shell and mass) and to Fucus biomass to satisfy homoscedasticity and normality requirements of the model.

Temperature was measured around 1 reef of each size. This means that substratum temperature effects were tested using an unreplicated factorial ANOVA model that was missing both among and within reef variance estimates. Thus reef size effect was confounded with site effect for these analyses.

Table 1. ANOVA showing the effect of reef size (RSize), orientation (Ort), distance (Dst), and among reef variability [R(RSize)] on velocity flow index (plaster erosion rate, $\mathrm{mg} \mathrm{s}^{-1}$ )

\begin{tabular}{|lrccc|}
\hline Source of variation & df & MS & $F$ & $\mathrm{p}$ \\
\hline RSize & 3 & $1.33 \times 10^{-6}$ & 0.096 & 0.9605 \\
R(RSize) & 12 & $1.409 \times 10^{-5}$ & 47.059 & 0.0001 \\
Ort & 5 & $1.981 \times 10^{-6}$ & 6.614 & 0.0001 \\
Dst & 3 & $1.352 \times 10^{-5}$ & 45.130 & 0.0001 \\
RSize $\times$ Ort & 15 & $9.241 \times 10^{-7}$ & 3.086 & 0.0001 \\
RSize $\times$ Dst & 9 & 2.536 & 8.468 & 0.0001 \\
Ort $\times$ Dst & 15 & 1.062 & 3.5471 & 0.0001 \\
RSize $\times$ Ort $\times$ Dst & 45 & 3.584 & 1.197 & 0.1966 \\
Error & 256 & $3.30 \times 10^{-7}$ & & \\
Corrected total & 363 & & & \\
\hline
\end{tabular}

The strength of the linear relationships between physical (i.e. flow velocity, flow index, substratum temperature) and biological (i.e. biomass of dominant species, growth of Mytilus) variables as a function of reef size was tested using multivariate regression models. Least-square multivariate regression was used to fit each biological variable to the 3 physical parameters for each reef size category. The contribution of each physical variable to the total fit was examined using squared semi-partial correlation coefficients giving the percentage of variability of the dependent variable explained by each physical variable entered into the model.

\section{RESULTS}

\section{Hydrodynamics}

Flow regime

The mean velocity of current meter flow at the western end of the study site was $0.05 \mathrm{~m} \mathrm{~s}^{-1}$ at $10 \mathrm{~cm}$ from the bottom and $0.111 \mathrm{~m} \mathrm{~s}^{-1}$ at $60 \mathrm{~cm}$ from the bottom. The current mean orientation relative to magnetic north was $94.0^{\circ}$ at $10 \mathrm{~cm}$ and $67.6^{\circ}$ at $60 \mathrm{~cm}$. At the eastern end of the study site, the mean flow velocity was $0.464 \mathrm{~m} \mathrm{~s}^{-1}$ and mean orientation was $81.2^{\circ}$ at $30 \mathrm{~cm}$ from the bottom. Flow reversal, common in the St. Lawrence Estuary during a tidal cycle, was never recorded at the study site from June to August 1995. Flow was always oriented eastward, approximately parallel to the shore, and usually varied between 60 and $100^{\circ}$ relative to magnetic north. These data agree with a hydrodynamic model of the whole Estuary, showing a permanent gyre circulating across our study site.

\section{Flow index}

The rate of plaster loss (flow index; $\mathrm{mg} \mathrm{s}^{-1}$ ) was significantly influenced by reef size interacting with orientation and distance from reefs (Table 1). The smallest reef induced a significantly lower flow velocity at $100 \mathrm{~cm}$ away from the reef than at $20 \mathrm{~cm}$ (Fig. 3B). The $76 \mathrm{~cm}$ reef had an effect at $60 \mathrm{~cm}$ and flow remained significantly less than at $20 \mathrm{~cm}$ at 100 and $140 \mathrm{~cm}$ (Fig. 3C). The $115 \mathrm{~cm}$ reef had a greater influence on flow and the flow index continued to drop significantly between 60 and $100 \mathrm{~cm}$ from the reef; this lower index was still seen $140 \mathrm{~cm}$ from the reefs (Fig. 3D). In summary, the larger the reef, the greater the effect of orientation and distance, indicating that scale affected the amplitude of the flow index patterns. There was a symmetrical flow index pattern around large reefs, 


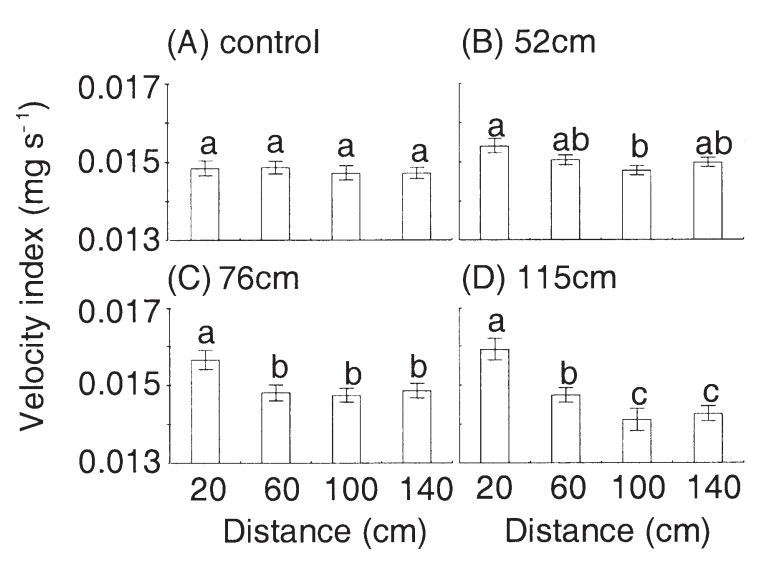

(E) $115 \mathrm{~cm}$

Flow index
$\left(\mathrm{mg}^{-1} \mathrm{~s}^{-1}\right)$

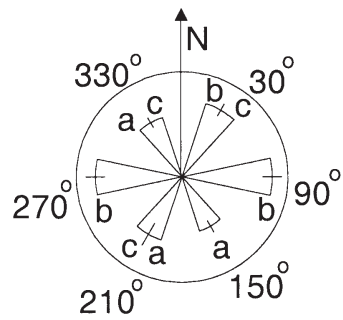

Fig. 3. Flow index (plaster dissolution rate, $\mathrm{mg} \mathrm{s}^{-1} \pm \mathrm{SE}, \mathrm{N}=24$ [A-D] or $N=16$ [E]) as a function of distance from the edge of control sites (A) and small (B), medium (C) and large (D) reefs. (E) Flow index at 6 orientations (all distances combined) around large reefs $(115 \mathrm{~cm})$. Letters above bars show significant differences among distances (A-D) or orientations (E) according to a least-squares means multiple comparisons test $(\alpha=0.01)$

with the index significantly higher along the $270^{\circ} / 90^{\circ}$ axis compared to along the $330^{\circ} / 150^{\circ}$ axis (Fig. 3E). Mean flow orientation as measured by the current meters when the water depth was $>0.5 \mathrm{~m}$ was $83.4^{\circ}$ during the period plaster cylinders were in place. The symmetrical plaster loss pattern around the large reefs suggests that plaster erosion was imposed by a flow along the $330^{\circ} / 150^{\circ}$ axis, and this was also the dominant wave direction which created a shoreward flow in shallow water through the interaction with topography at the scale of the study area (F.G. pers. obs.).

\section{Hydrodynamic finite-element model}

We simulated a mean flow velocity of $0.067 \mathrm{~m} \mathrm{~s}^{-1}$ over an intertidal platform at time $t=T / 4$, where $T$ is the tidal period $(12.4 \mathrm{~h})$. The cylinder reefs induced 2 major features. There was a velocity decrease on the downstream side of the reefs (60 to $100^{\circ}$ according to current meter data) and a symmetrical flow acceleration on both sides along the main flow axis, near the edge of cylinders (Fig. 4). The model uncovered strong scaling of these features as a function of reef size. The ratio of accelerated flow velocity over minimum downstream velocity was 1.57 around the small reef, 2.15 around the medium reef and 2.99 around the largest.

\section{Substratum temperature}

There was a significant interaction between reef size and the distance from reefs on mean substratum temperature during low tide (Table 2). There was no dis-
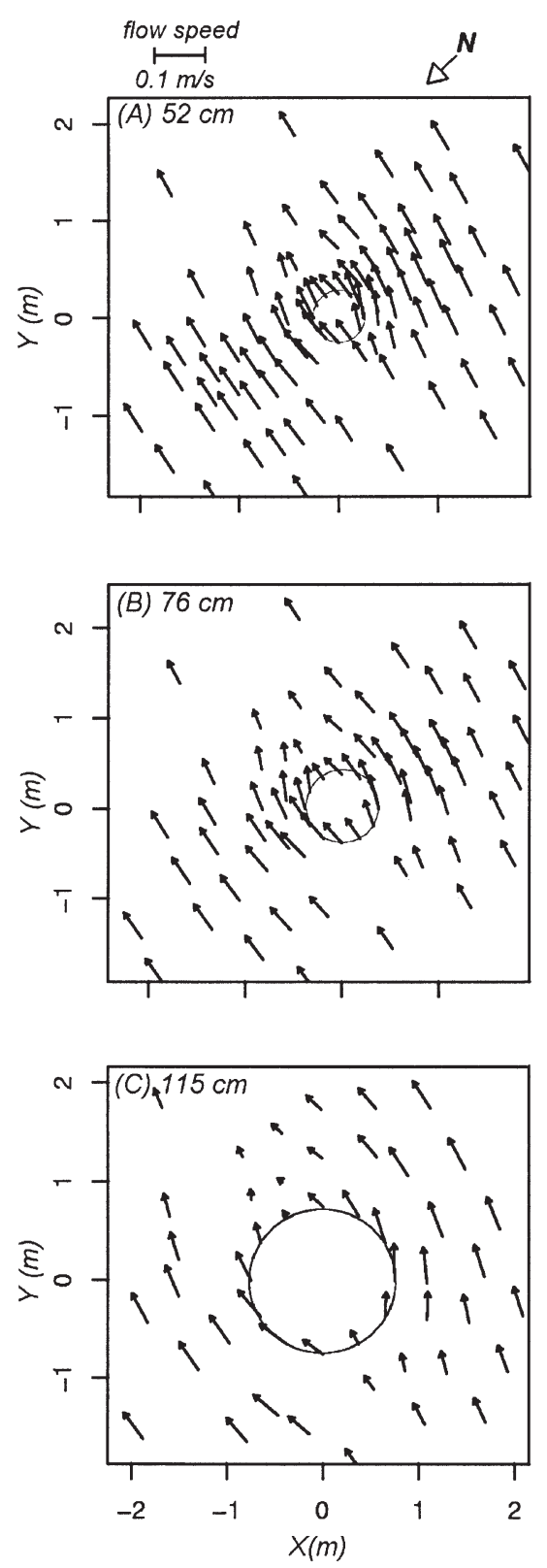

Fig. 4. Finite-element hydrodynamic model outputs showing flow velocity $\left(\mathrm{m} \mathrm{s}^{-1}\right)$ and orientation around a small $(52 \mathrm{~cm} ; \mathrm{A})$, a medium $(76 \mathrm{~cm} ; \mathrm{B})$ and a large $(115 \mathrm{~cm} ; \mathrm{C})$ reef 
Table 2. ANOVA showing the effect of reef size (RSize), orientation (Ort), and distance (Dst) on substratum temperature $\left({ }^{\circ} \mathrm{C}\right)$

\begin{tabular}{|lrcrc|}
\hline Source of variation & df & MS & $F$ & $\mathrm{p}$ \\
\hline RSize & 3 & 5.9345 & 51.74 & 0.0001 \\
Ort & 5 & 0.6030 & 5.26 & 0.0007 \\
Dst & 3 & 2.1186 & 18.47 & 0.0001 \\
RSize $\times$ Ort & 15 & 0.2134 & 1.86 & 0.0550 \\
RSize $\times$ Dst & 9 & 0.3320 & 2.89 & 0.0087 \\
Ort $\times$ Dst & 15 & 0.1210 & 1.05 & 0.4220 \\
Error & 45 & 0.1147 & & \\
Corrected total & 95 & & & \\
& & & & \\
\hline
\end{tabular}

Table 3. ANOVA showing the effect of reef size (RSize), year $(\mathrm{Y})$, orientation (Ort), distance (Dst), and among-replicate reef variability [R(RSize)] on the biomass ( $\mathrm{g}$ ) of Mytilus

\begin{tabular}{|lrrrc|}
\hline Source of variation & df & MS & $F$ & $\mathrm{p}$ \\
\hline RSize & 3 & 70.4851 & 3.8673 & 0.0411 \\
R $($ RSize $)$ & 11 & 18.2561 & 3.6606 & 0.0001 \\
Y & 1 & 402.4029 & 80.6886 & 0.0001 \\
Ort & 5 & 4.2947 & 0.8612 & 0.5073 \\
Dst & 2 & 3.0386 & 0.6093 & 0.5443 \\
RSize $\times$ Y & 3 & 1.8911 & 0.3792 & 0.7681 \\
RSize $\times$ Ort & 15 & 9.5032 & 1.9055 & 0.0214 \\
RSize $\times$ Dst & 6 & 3.0725 & 0.6161 & 0.7175 \\
Y $\times$ Ort & 5 & 6.1043 & 1.2240 & 0.2971 \\
Y $\times$ Dst & 2 & 1.4777 & 0.2963 & 0.7437 \\
Ort $\times$ Dst & 10 & 2.0481 & 0.4107 & 0.9414 \\
RSize $\times$ Y $\times$ Ort & 15 & 6.3652 & 1.2763 & 0.2139 \\
RSize $\times$ Y $\times$ Dst & 6 & 7.2397 & 1.4517 & 0.1938 \\
RSize $\times$ Ort $\times$ Dst & 30 & 6.2526 & 1.2538 & 0.1723 \\
Y $\times$ Ort $\times$ Dst & 10 & 3.5755 & 0.7169 & 0.7086 \\
RSize $\times$ Y $\times$ Ort $\times$ Dst & 30 & 4.1869 & 0.8395 & 0.7116 \\
Error & 380 & 4.9871 & & \\
Total & 534 & & & \\
\hline
\end{tabular}

tance effect on substratum temperature at control sites (Fig. 5A) but temperature was significantly lower at the first distance for the small and medium reefs compared to other distances (Fig. 5B,C). Around large reefs, temperature decreased from the farthest to the closest distance categories (Fig. 5D). In contrast to flow index patterns, the spatial limits but not the amplitude of the temperature gradient were influenced by reef size, despite some variability in amplitude among reef sizes and unreplicated reef size treatment.

\section{Community characteristics}

There were significant annual biomass differences for all dominant species. Reef size significantly interacted with annual changes in the biomass of Littorina saxatilis and L. obtusata but Mytilus was independently affected between years and by reef size. Spatial

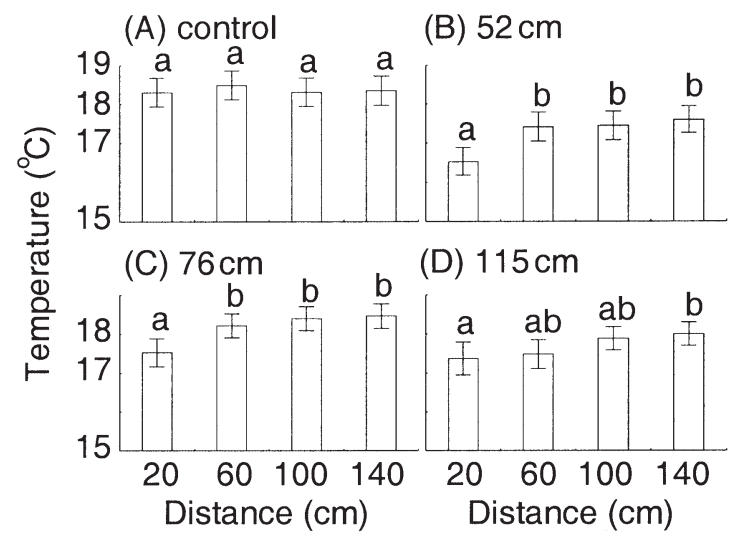

Fig. 5. Substratum temperature $\left({ }^{\circ} \mathrm{C} \pm \mathrm{SE}, \mathrm{N}=6\right)$ as a function of distance from the edge of a control site (A) and a small $(52 \mathrm{~cm} ; \mathrm{B})$, a medium $(76 \mathrm{~cm} ; \mathrm{C})$ and a large $(155 \mathrm{~cm} ; \mathrm{D})$ reef. Different letters above bars show significant differences between distance categories according to a least-squares means multiple comparisons test $(\alpha=0.01)$

patterns of Mytilus and L. saxatilis biomass and density around large reefs were significant and depended on body size. There was also a significant Fucus biomass distance gradient around large reefs.

\section{Impact of reef size}

There were significant year and scale effects on Mytilus biomass with no interaction (Table 3). Biomass was significantly higher in 1995 than in 1994 and higher around larger reefs compared to controls (Fig. 6A). Mytilus biomass was the dominant around large reefs in 1995 and appeared to be responsible for both significant effects (Fig. 6A).

Littorina saxatilis biomass was significantly influenced by interactions between year and scale (Table 4). There was an increase in L. saxatilis biomass between 1994 and 1995 at control sites, but this interannual difference did not hold and was progressively reversed with increasing reef size (Fig. 6B). Around large reefs, L. saxatilis biomass was less in 1995 than in 1994.

There was a significant interaction between year and reef size on Littorina obtusata biomass (Table 4). While maximum biomass was observed around medium-size reefs in 1994, biomass was at a minimum and significantly lower around medium-size reefs compared to control sites a year later (Fig. 6C).

\section{Spatial patterns of biomass and density}

In 1995, differences in spatial patterns of biomass and density were significant only around large reefs 

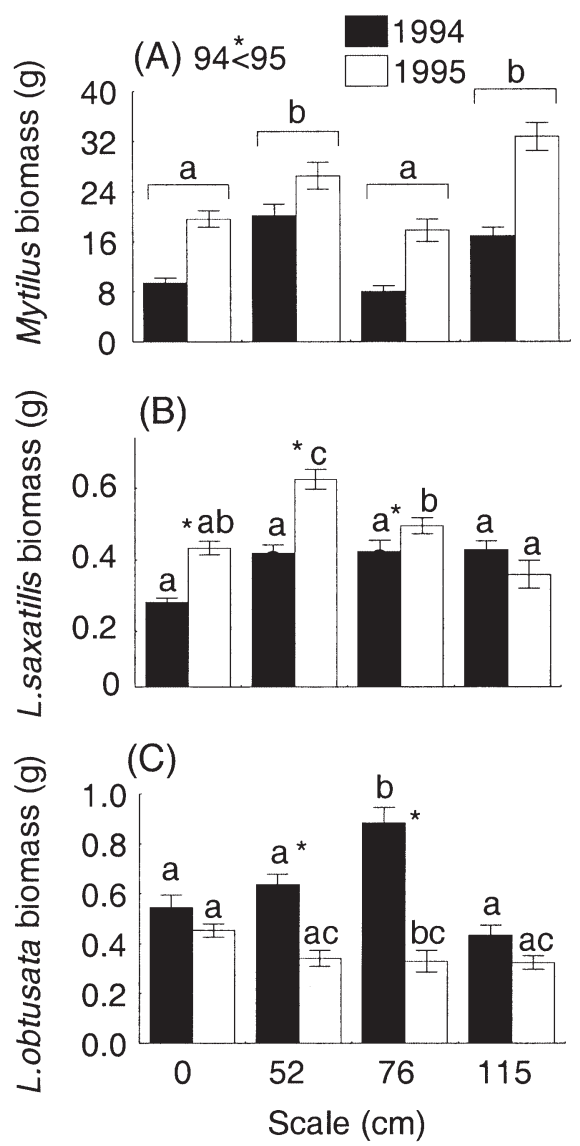

Fig. 6. Biomass $(\mathrm{g} \pm \mathrm{SE}$ ) of dominant species before (1994; black bars) and 1 yr after (1995; white bars) installation of reefs of different sizes (Scale). Different letters above bars show significant differences among scale categories and stars represent significant differences between years according to a least-squares means multiple comparisons test $(\alpha=0.01)$

and were symmetrical along the $270^{\circ} / 90^{\circ}$ axis. There was a significant interaction between scale and orientation on Mytilus biomass (Table 5), which was significantly less between $60^{\circ}$ and $120^{\circ}$ compared to other orientations around large reefs (Fig. 7A). The density of individuals $>2 \mathrm{~mm}$ was linked to this pattern (Fig. 8A,B). Large (>2 mm) Mytilus density around the large reefs was less between $60^{\circ}$ and $120^{\circ}$ compared to between $240^{\circ}$ and $300^{\circ}$; however, this pattern was significant for individuals between 2 and $8 \mathrm{~mm}$, but not for individuals $>8 \mathrm{~mm}$ (Table 6, Fig. 8A,B). Littorina saxatilis biomass distribution was similar with the $0^{\circ}$ to $60^{\circ}$ and $120^{\circ}$ to $180^{\circ}$ orientation categories, having lower values than orientations between $240^{\circ}$ and $270^{\circ}$ (Table 5, Fig. 7B). L. saxatilis density, however, was significantly greater around medium cylinders, but with no oriented density pattern (Table 6, Fig. 8C). There was a significant interaction between reef size and distance from reefs on Fucus biomass (Table 5).
Fucus biomass increased with distance from large reefs (Fig. 7C) and was significantly lower around reefs compared to controls (Fig. 7D). Reef size had a significant effect on L. obtusata density (Table 6), and L. obtusata was significantly less abundant around cylinders compared to control sites (Fig. 8D).

\section{Growth of Mytilus}

There was a significant influence of distance from the reefs on both shell length and weight growth (Table 7, Fig. 9A). There was no significant influence of reef size on growth, but shell growth at $20 \mathrm{~cm}$ was 1.36 times greater than growth at $140 \mathrm{~cm}$ on control

Table 4. ANOVA showing the effect of reef size (RSize), year $(\mathrm{Y})$, orientation (Ort), distance (Dst), and among-replicate reef variability [R(RSize)] on the biomass ( $\mathrm{g}$ ) of Littorina obtusata and Littorina saxatilis

\begin{tabular}{|lrccc|}
\hline Source of variation & df & MS & $F$ & $\mathrm{p}$ \\
\hline Littorina obtusata & & & & \\
RSize & 3 & 0.0863 & 0.1412 & 0.9332 \\
R(RSize) & 11 & 0.6125 & 5.0632 & 0.0001 \\
Y & 1 & 1.9976 & 16.5126 & 0.0001 \\
Ort & 5 & 0.1063 & 0.8784 & 0.4955 \\
Dst & 2 & 0.4164 & 3.4424 & 0.0330 \\
RSize $\times$ Y & 3 & 0.8606 & 7.1139 & 0.0001 \\
RSize $\times$ Ort & 15 & 0.1036 & 0.8567 & 0.6136 \\
RSize $\times$ Dst & 6 & 0.1863 & 1.5399 & 0.1639 \\
Y $\times$ Ort & 5 & 0.0510 & 0.4215 & 0.8337 \\
Y $\times$ Dst & 2 & 0.0050 & 0.0410 & 0.9598 \\
Ort $\times$ Dst & 10 & 0.0859 & 0.7103 & 0.7149 \\
RSize $\times$ Y $\times$ Ort & 15 & 0.1074 & 0.8882 & 0.5778 \\
RSize $\times$ Y $\times$ Dst & 6 & 0.2387 & 1.9731 & 0.0685 \\
RSize $\times$ Ort $\times$ Dst & 30 & 0.0730 & 0.6031 & 0.9531 \\
Y $\times$ Ort $\times$ Dst & 10 & 0.0898 & 0.7426 & 0.6841 \\
RSize $\times$ Y $\times$ Ort $\times$ Dst & 30 & 0.0970 & 0.8017 & 0.7643 \\
Error & 380 & 0.1210 & & \\
Total & 534 & & & \\
Littorina saxatilis & & & & \\
RSize & 3 & 0.2965 & 0.9356 & 0.4562 \\
R $($ RSize $)$ & 11 & 0.3175 & 6.9364 & 0.0001 \\
Y & 1 & 2.2920 & 50.0768 & 0.0001 \\
Ort & 5 & 0.0318 & 0.6948 & 0.6276 \\
Dst & 2 & 0.0611 & 1.3358 & 0.2642 \\
RSize $\times$ Y & 3 & 0.3169 & 6.9231 & 0.0002 \\
RSize $\times$ Ort & 15 & 0.0774 & 1.6908 & 0.0504 \\
RSize $\times$ Dst & 6 & 0.0175 & 0.3829 & 0.8899 \\
Y $\times$ Ort & 5 & 0.0346 & 0.7564 & 0.5818 \\
Y $\times$ Dst & 2 & 0.0645 & 1.4100 & 0.2454 \\
Ort $\times$ Dst & 10 & 0.0137 & 0.2986 & 0.9813 \\
RSize $\times$ Y $\times$ Ort & 15 & 0.0585 & 1.2777 & 0.2131 \\
RSize $\times$ Y $\times$ Dst & 6 & 0.0413 & 0.9019 & 0.4934 \\
Csize $\times$ Ort $\times$ Dst & 30 & 0.0344 & 0.7511 & 0.8279 \\
Y $\times$ Ort $\times$ Dst & 10 & 0.0387 & 0.8447 & 0.5858 \\
RSize $\times$ Y $\times$ Ort $\times$ Dst & 30 & 0.0293 & 0.6400 & 0.9309 \\
Error & & & & \\
Total & & & & \\
\hline & & & & \\
\hline
\end{tabular}


sites, while this ratio was 1.61 around $76 \mathrm{~cm}$ reefs (Fig. 9B). Orientation around reefs did not influence Mytilus growth.

\section{Flow and biological variables}

The regression model outcome indicated that flow index, flow velocity, and substratum temperature explained up to $77.2 \%$ of Mytilus shell growth around medium reefs and $51.7 \%$ of Mytilus biomass around large reefs. Relationships between physical and biological variables were highly dependent on reef size. Regression models were not significant at control sites and small reefs; however $\mathrm{R}^{2}$ values increased with reef size, with a maximum for medium and large reefs

Table 5. ANOVA showing the effect of reef size (RSize), orientation (Ort), distance (Dst), among-reef [R(RSize)] and within-reef [Ort $\times$ Dst $\times \mathrm{R}(\mathrm{RSize})]$ variability on Littorina saxatilis, Mytilus and Fucus sp. biomass (g)

\begin{tabular}{|lrrcc|}
\hline Source of variation & df & MS & $F$ & $\mathrm{p}$ \\
\hline Littorina saxatilis & & & & \\
RSize & 3 & 2.6702 & 3.1852 & 0.0631 \\
R $($ RSize $)$ & 11 & 1.0148 & 5.8665 & 0.0001 \\
Ort & 5 & 0.1274 & 0.7373 & 0.5963 \\
Dst & 3 & 0.0310 & 0.1798 & 0.9100 \\
RSize $\times$ Ort & 15 & 0.3439 & 1.9877 & 0.0172 \\
RSize $\times$ Dst & 9 & 0.0416 & 0.2407 & 0.9881 \\
Ort $\times$ Dst & 15 & 0.1308 & 0.7542 & 0.7270 \\
RSize $\times$ Ort $\times$ Dst & 43 & 0.1018 & 0.5862 & 0.9807 \\
Ort $\times$ Dst $\times$ R(RSize) & 209 & 0.1739 & 1.2522 & 0.0175 \\
Error & 787 & 0.1389 & & \\
Total & 1100 & & & \\
Mytilus & & & & \\
RSize & 3 & 45.3995 & 0.8717 & 0.4830 \\
R(RSize) & 11 & 63.4382 & 6.6469 & 0.0001 \\
Ort & 5 & 25.0089 & 2.6258 & 0.0250 \\
Dst & 3 & 5.2260 & 0.5509 & 0.6481 \\
RSize $\times$ Ort & 15 & 17.6479 & 1.8482 & 0.0299 \\
RSize $\times$ Dst & 9 & 9.3625 & 0.9815 & 0.4562 \\
Ort $\times$ Dst & 15 & 9.2819 & 0.9679 & 0.4903 \\
RSize $\times$ Ort $\times$ Dst & 43 & 7.4034 & 0.7697 & 0.8460 \\
Ort $\times$ Dst $\times$ R(RSize) & 209 & 9.6460 & 1.6492 & 0.0001 \\
Error & 787 & 5.8491 & & \\
Total & 1100 & & & \\
Fucus sp. & & & & \\
RSize & 3 & 1.9489 & 0.1066 & 0.9545 \\
R $($ RSize $)$ & 11 & 22.7605 & 17.0283 & 0.0001 \\
Ort & 5 & 4.4444 & 3.3335 & 0.0064 \\
Dst & 3 & 2.5630 & 1.9316 & 0.1254 \\
RSize $\times$ Ort & 15 & 1.9350 & 1.4468 & 0.1278 \\
RSize $\times$ Dst & 9 & 3.7760 & 2.8268 & 0.0037 \\
Ort $\times$ Dst & 15 & 0.8520 & 0.6337 & 0.8452 \\
RSize $\times$ Ort $\times$ Dst & 43 & 1.2580 & 0.9323 & 0.5952 \\
Ort $\times$ Dst $\times$ R(RSize) & 209 & 1.3541 & 1.9200 & 0.0001 \\
Error & 787 & 0.7052 & & \\
Total & 1100 & & & \\
& & & & \\
\hline
\end{tabular}

Table 6. ANOVA showing the effect of reef size (RSize), orientation (Ort), distance (Dst), and among-replicate reef variability [R(RSize)], on Littorina obtusata, Littorina saxatilis and 2-8 mm Mytilus density

\begin{tabular}{|lrrcc|}
\hline Source of variation & df & MS & $F$ & $\mathrm{p}$ \\
\hline Littorina obtusata & & & & \\
RSize & 3 & 2077.5660 & 6.2176 & 0.0100 \\
R(RSize) & 11 & 334.1418 & 6.6871 & 0.0001 \\
Ort & 1 & 2.0920 & 0.0419 & 0.8386 \\
Dst & 2 & 54.5524 & 1.0917 & 0.3428 \\
RSize $\times$ Ort & 3 & 61.3855 & 1.2285 & 0.3081 \\
RSize $\times$ Dst & 6 & 24.8867 & 0.4981 & 0.8071 \\
Ort $\times$ Dst & 2 & 43.6943 & 0.8744 & 0.4228 \\
RSize $\times$ Ort $\times$ Dst & 6 & 13.9762 & 0.2797 & 0.9442 \\
Error & 55 & 49.9679 & & \\
Total & 89 & & & \\
Littorina saxatilis & & & & \\
RSize & 3 & 1785.3535 & 2.1084 & 0.1572 \\
R $($ RSize $)$ & 11 & 846.7687 & 8.9418 & 0.0001 \\
Ort & 1 & 0.0062 & $6.59 E-5$ & 0.9936 \\
Dst & 2 & 189.3974 & 2.0000 & 0.1451 \\
RSize $\times$ Ort & 3 & 268.7808 & 2.8383 & 0.0463 \\
RSize $\times$ Dst & 6 & 119.3516 & 1.2603 & 0.2908 \\
Ort $\times$ Dst & 2 & 198.8257 & 2.0996 & 0.1322 \\
RSize $\times$ Ort $\times$ Dst & 6 & 140.2458 & 1.4810 & 0.2018 \\
Error & 55 & 94.6982 & & \\
Total & 89 & & & \\
Mytilus, 2-8 mm & & & & \\
RSize & 3 & 274.0545 & 0.0713 & 0.9741 \\
R $($ RSize $)$ & 11 & 3846.2087 & 7.3532 & 0.0001 \\
Ort & 1 & 2534.3092 & 4.8451 & 0.0319 \\
Dst & 2 & 100.3973 & 0.1919 & 0.8259 \\
RSize $\times$ Ort & 3 & 1321.6342 & 2.5267 & 0.0668 \\
RSize $\times$ Dst & 6 & 144.4834 & 0.2762 & 0.9458 \\
Ort $\times$ Dst & 2 & 571.4271 & 1.0925 & 0.3426 \\
RSize $\times$ Ort $\times$ Dst & 6 & 470.5051 & 0.8995 & 0.5020 \\
Error & 55 & 523.0683 & & \\
Total & 89 & & & \\
& & & & \\
\hline
\end{tabular}

(Fig. 10A,B). For medium-size reefs, where the Mytilus growth gradient was maximum (Fig. 9B), temperature alone explained $66.4 \%$ of Mytilus shell growth variability (Fig. 10B,D). Around large reefs, Mytilus biomass variance was best explained by flow velocity $(27 \%$; Fig. 10A,C). The regression model was not significant for Mytilus density.

\section{DISCUSSION}

Topographic heterogeneity in the form of concrete cylinder reefs had a significant and scale-dependent influence on both surrounding physical (hydrodynamics, substratum temperature) and biological (biomass, density, growth) variables. There were significant differences in the scaling of hydrodynamic and substratum temperature patterns as a function of reef size 


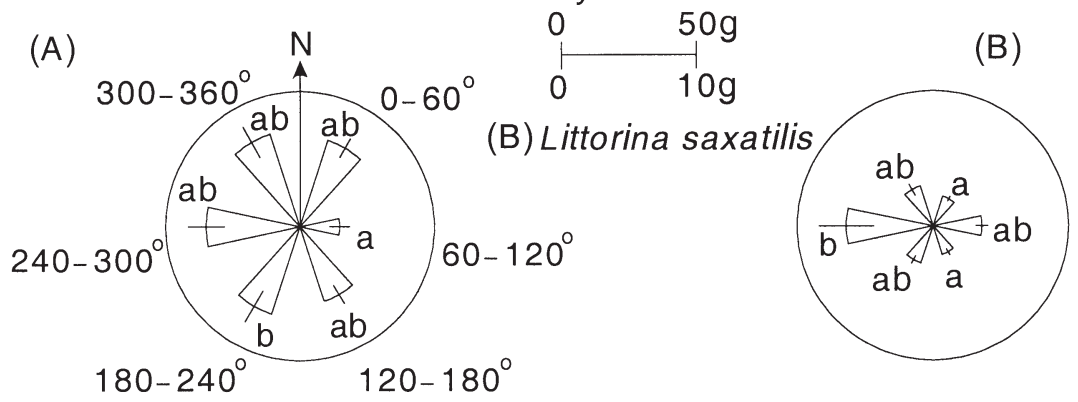

(A) Mytilus edulis

(C) $115 \mathrm{~cm}$

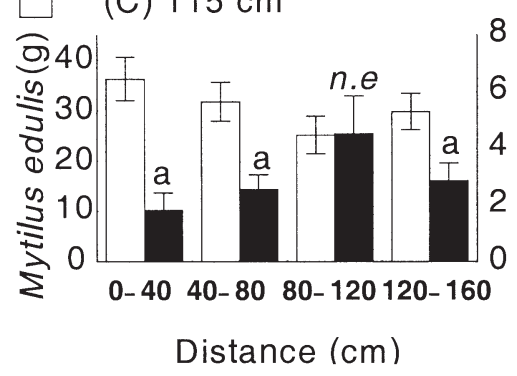

(D) $0-40 \mathrm{~cm}$

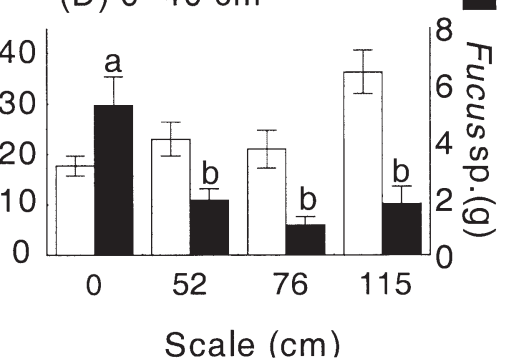

Fig. 7. Biomass $(\mathrm{g} \pm \mathrm{SE})$ of Mytilus (A) and Littorina saxatilis (B) as a function of orientation around large $(115 \mathrm{~cm})$ reefs. (C,D) Mytilus and Fucus sp. biomass as a function of distance from the edge of large reefs (C) and within $40 \mathrm{~cm}$ from the edge of reefs as a function of their size (D). Different letters above bars show significant differences among orientation (A-B), distance $(C)$ or scale (D) categories according to a least-squares means multiple comparisons test ( $\alpha=0.01$, n.e $=$ nonestimable)

(topographic scale). Reef size also determined the form of biological patterns in the vicinity of the artificial reefs and had a significant effect on the dominant species between sampling years. We found a scale-dependent relationship between abiotic and biotic parameters and identified dominant biological and physical variables that interact in the vicinity of medium and larger reefs.

\section{Scaling topographically generated environmental patterns}

The scaling of hydrodynamic patterns created by reefs was investigated theoretically and experimentally (Lighthill 1986). This scaling can best be described using the nondimensional Reynolds number $(\operatorname{Re}=D U / v)$, relating ambient flow velocity $(U)$, reef size $(D)$ and fluid viscosity $(v)$ to the spatial structure of flow over any object or surface. The Re number can describe the increase in turbulence around a cylinder. When flow velocity and viscosity are held constant, scaling up the topography results in an increase in turbulence levels above the substratum. More precisely, high Re values $\left(>10^{5}\right)$ are associated with a fully turbulent boundary layer and low shear stress over the surface of the cylinder. These properties are responsible for an area of low flow velocity on the downstream side of cylindrical structures (Tritton 1988, Granger 1995). Flow acceleration on 2 sides of a cylinder is linked to increased pressure around the cylinder. From these considerations, we can expect hydrodynamic properties to scale nonlinearly with topographic heterogeneity. Specific hydrodynamic patterns around a cylinder, such as a decrease in flow velocity, depend on scale thresholds, since their strength changes nonlinearly as a function of scale. The predicted result is that the spatial extent and amplitude of hydrodynamic properties will increase with topographic scale.

Plaster erosion patterns around large reefs were characteristic of shoreward-oriented ambient flow, along the $330^{\circ} / 150^{\circ}$ axis (Fig. 3), but the current meters showed that flow in $>0.5 \mathrm{~m}$ water depth was oriented eastward, along the $270^{\circ} / 90^{\circ}$ axis. This suggests that hydrodynamic conditions are different close to the bottom in shallow water compared to $>0.5 \mathrm{~m}$ water. The flow index determined by plaster erosion integrates all

\section{$\begin{array}{ll}\text { (A) Mytilus; } 2-8 \mathrm{~mm} & \text { (B) Mytilus ; }>8 \mathrm{~mm}\end{array}$}

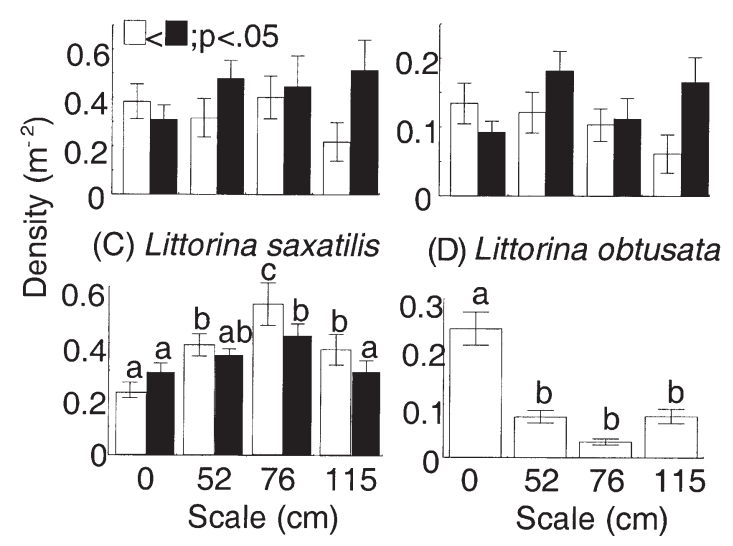

Fig. 8. Density (number of individuals, $\pm \mathrm{SE}$ ) of the dominant species measured upstream $\left(240^{\circ}\right.$ to $300^{\circ}$; black bars $)$, or downstream $\left(60^{\circ}\right.$ to $120^{\circ}$; white bars) of reefs or at both orientations combined (D) as a function of reef size (Scale; $\mathrm{cm}$ ). Different letters above bars show significant differences among scale categories according to a least-squares means multiple comparisons test $(\alpha=0.01)$ 
Table 7. ANOVA showing the effect of reef size (RSize), orientation (Ort), distance (Dst), among-reef [R(RSize)] and within-reef $[$ Ort $\times$ Dst $\times \mathrm{R}(\mathrm{RSize})]$ variability on Mytilus weight $(\mathrm{g})$ and shell $(\mathrm{mm})$ growth

\begin{tabular}{|c|c|c|c|c|}
\hline Source of variation & $\mathrm{df}$ & MS & $F$ & $\mathrm{p}$ \\
\hline \multicolumn{5}{|l|}{ Weight growth } \\
\hline RSize & 3 & 0.0684 & 1.6173 & 0.2373 \\
\hline R(RSize) & 12 & 0.05201 & 14.6673 & 0.0001 \\
\hline Ort & 5 & 0.0041 & 1.4950 & 0.1924 \\
\hline Dst & 2 & 0.0711 & 18.7170 & 0.0001 \\
\hline RSize $\times$ Ort & 15 & 0.0042 & 1.2975 & 0.2050 \\
\hline RSize $\times$ Dst & 6 & 0.0011 & 0.4664 & 0.8328 \\
\hline Ort $\times$ Dst & 10 & 0.0036 & 1.2810 & 0.2423 \\
\hline RSize $\times$ Ort $\times$ Dst & 30 & 0.0037 & 1.0804 & 0.3622 \\
\hline Ort $\times$ Dst $\times$ R $($ RSize $)$ & 203 & 0.0033 & 1.2626 & 0.0159 \\
\hline Error & 746 & 0.0027 & & \\
\hline Total & 1032 & & & \\
\hline \multicolumn{5}{|l|}{ Shell growth } \\
\hline RSize & 3 & 2.2522 & 1.2044 & 0.3500 \\
\hline R(RSize) & 12 & 1.8807 & 19.8200 & 0.0001 \\
\hline Ort & 5 & 0.1188 & 1.2533 & 0.2853 \\
\hline Dst & 2 & 2.1903 & 23.1246 & 0.0001 \\
\hline RSize $\times$ Ort & 15 & 0.1223 & 1.2877 & 0.2113 \\
\hline RSize $\times$ Dst & 6 & 0.0721 & 0.7602 & 0.6020 \\
\hline Ort $\times$ Dst & 10 & 0.1320 & 1.3913 & 0.1855 \\
\hline RSize $\times$ Ort $\times$ Dst & 30 & 0.0883 & 0.9273 & 0.5796 \\
\hline Ort $\times$ Dst $\times$ R $($ RSize $)$ & 203 & 0.0965 & 1.4316 & 0.0004 \\
\hline Error & 746 & 0.0674 & & \\
\hline Total & 1032 & & & \\
\hline
\end{tabular}
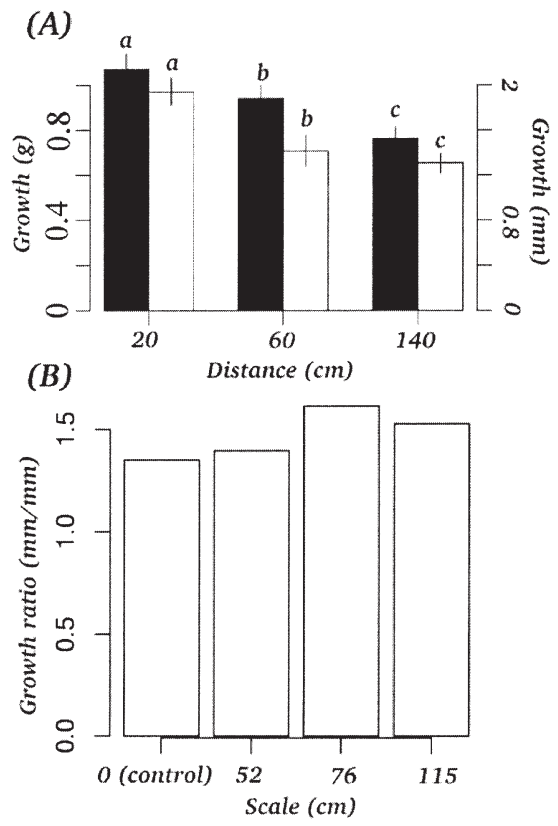

Fig. 9. (A) Mytilus weight ( $\mathrm{g} \pm \mathrm{SE}$, black bars) and shell (mm $\pm \mathrm{SE}$, white bars) growth as a function of distance from reefs $(\mathrm{cm})$. Different letters above bars reveal significant differences among distances. (B) Ratio of shell growth at $20 \mathrm{~cm}$ over shell growth at $140 \mathrm{~cm}$ from reefs as a function of reef size. Different letters above bars show significant differences between distance categories according to a Bonferoni multiple comparisons test $(\alpha=0.01)$

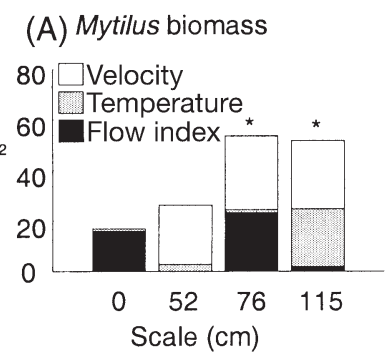

(B) Mytilus growth ( $\mathrm{mm})$

(C) Scale $=115 \mathrm{~cm}$
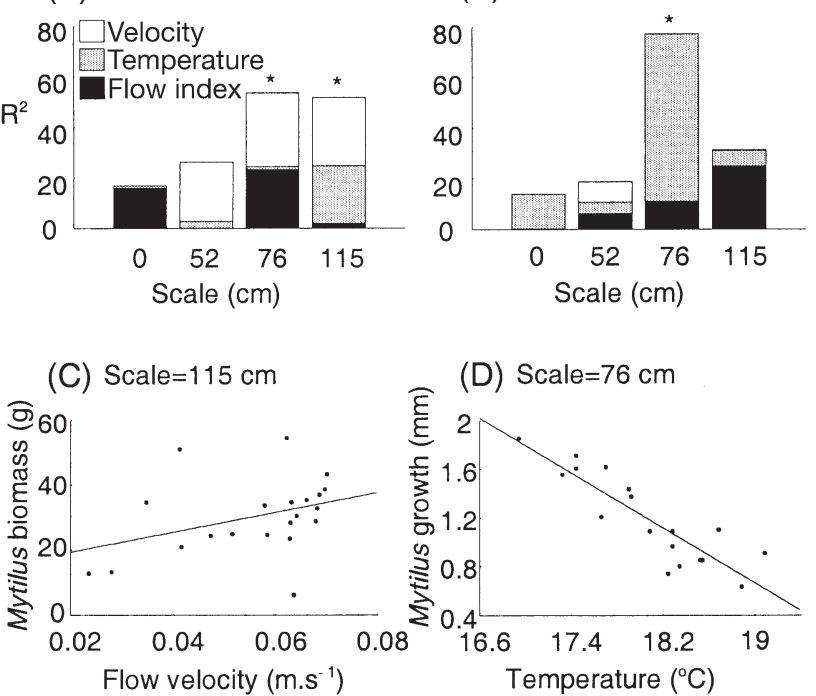

(D) Scale $=76 \mathrm{~cm}$

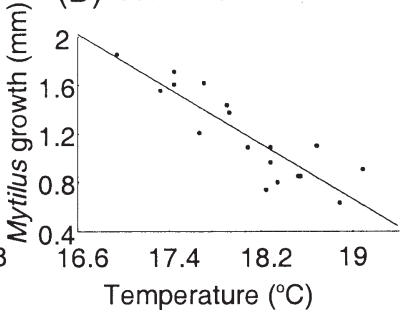

Fig. 10. (A,B) Percentage of variability in Mytilus biomass ( $g$; A) and shell growth $(\mathrm{mm} ; \mathrm{B})$ explained by flow velocity (white bars), substratum temperature (gray bars) and flow index (black bars), represented as the contribution of each independent variable (squared semi-partial correlation coefficients) to the total $\mathrm{R}^{2}$ of a multivariate regression model. Stars above bars show statistically significant regression models. (C,D) Influence of flow velocity on Mytilus biomass around large reefs (C) and of substratum temperature on Mytilus shell growth around medium reefs (D)

factors acting on exposed surfaces (turbulence, wave action in shallow water) and may be considered as an index of turbulent sheer stress or 'intensity of water motion' (Komatsu \& Kawai 1992).

The flow index confirmed the expected scaling of both the spatial extent and amplitude of patterns with reef size. The main pattern of water motion intensity around reefs was a distance gradient that suggested greater water motion near the reef's edge. This gradient grew in amplitude and spatial extent with topographic scale in agreement with the theory and observations from fluid mechanics.

Temperature data integrated over a 6 d temporal scale averaged out short-term differences caused by the interactions between the time of low tide and sun angle. There were temperature gradients around the artificial reefs, but the scaling of the substratum temperature with topographic scales was different from that of hydrodynamics. There was a clear distance gradient in substratum temperature from the reef edges. We found evidence that reef size linearly influenced the shaded area but did not affect the degree of shading, i.e. the temperature difference between shaded and nonshaded areas. Hydrodynamic scaling resulted in the creation of significant oriented patterns around large reefs, but no such scale threshold was observed 
for substratum temperature. These scaling differences for different factors show that in the intertidal zone, both high and low tide phases were characterized by environmental cascades of events induced by topographic heterogeneity, each with a specific set of scaling rules.

\section{Individual versus population level response}

In intertidal ecosystems, physical factors can control many aspects of benthic communities. During low tide, temperature and desiccation stress are major factors limiting benthic species distribution in the high intertidal (Suchanek 1985). During high tide, hydrodynamic properties can influence key biological processes. For example, flow velocity determines larval and food flux for suspension feeders, thus influencing recruitment and growth (Fréchette \& Bourget 1985, Wildish et al. 1987). Turbulent diffusion influences settlement (Harvey et al. 1995) and feeding rates (Nowell \& Jumars 1984), while wave force influences maximum body size (Gaylord et al. 1994), fertilization (Denny \& Shibata 1989) and post-settlement mortality (Connell 1961). The dominant species at our study site, Mytilus, is known to experience mortality from desiccation and high temperature in the upper intertidal (Seed \& Suchanek 1992), and individuals usually aggregate to form 3D matrices (mussel beds). Within the matrix, desiccation stress may be less as moisture is retained (Helmuth 1998), but food becomes limiting within the boundary layer and may limit growth (Fréchette et al. 1989). Increasing the flow velocity over a Mytilus bed could prevent food depletion by increasing vertical turbulent diffusion within the boundary layer (Butman et al. 1994). Solitary individual mussels could be more limited by desiccation stress than by flow velocity, since they are not protected from desiccation and are less likely to compete for food with congeners than those individuals within a mussel bed.

When the growth rate of individual mussels (17 to $20 \mathrm{~mm}$ initial shell length) was measured as a function of position around the artificial reefs, there was a linear decreasing gradient with distance away from reefs which was greatest around the medium reefs. The growth patterns were similar to substratum temperature patterns and were not strongly linked to reef size or influenced by orientation. Moreover, growth rate of individuals with shell length used in our experiment was best explained around medium reefs by the negative influence of substratum temperature (squared semi-partial correlation $=0.78$; Fig. 10B,D). Our results thus suggest that substratum temperature was an indication of shading. In turn, shading has a primary influ- ence on desiccation stress and was a major factor mediating individual response of Mytilus to topographic heterogeneity. However, wind velocity patterns are also directly influenced by topographic heterogeneity during low tide and may also influence desiccation stress.

Naturally occurring Mytilus biomass was significantly less downstream of the large reefs. There was also a decrease of large mussel density downstream of large reefs. Patterns of abundance for Mytilus therefore suggest a topographic scale threshold which results in the appearance of variations in abundance only above a minimum (threshold) topographic scale. Around large reefs, flow velocity best explained Mytilus biomass, which was positively influenced by flow velocity as simulated by the finite-element model. In natural populations individuals are mostly found aggregated in mussel beds, and flow velocity, as a determinant of boundary-layer structure, is the dominant mediating factor of mussel response to topographic heterogeneity. The dominant contribution of large individuals ( $>2 \mathrm{~mm}$ ) to the biomass patterns suggests that increased size by way of growth was likely the biological link between flow velocity and mussel biomass. Changes in food availability would create the emergence of patterns, although active migration could also influence patterning.

Other abundant species, Littorina saxatilis and Fucus sp., also showed spatial patterns with a significant influence of orientation or distance, but these patterns were significant only around large reefs and were opposite to the Mytilus patterns. Mussel beds are reported to increase colonization by soft substratum fauna that develop within beds (Tsuchiya \& Nishihira 1995, Svane \& Setyobudiandi 1996), but Fucus sp. interacts directly with mussels for primary substratum colonization (McCook \& Chapman 1991). Since the dominance pattern between Mytilus and Fucus sp. depends on environmental conditions (McCook \& Chapman 1991, Petraitis 1987), the same topographically induced areas that favor mussel development and dominance could decrease Fucus sp. abundance.

\section{Scaling the influence of topography on communities}

Increased environmental heterogeneity has often been linked to increased species diversity (Simpson 1964, August 1983). The mechanisms invoked usually involve multiplication of habitat types allowing more species to cohabit without being competitively excluded or by creating local environmental conditions allowing viability of species otherwise unable to survive or reproduce (King \& Pimm 1983, Tilman \& Pacala 1993). Environmental heterogeneity can also 
generate complex biotic-abiotic interactions leading to complex spatial patterns. There is often nonlinear scaling of environmental heterogeneity that influences benthic communities, with specific scale ranges matching key physical or biological processes at the individual, population or community level (Archambault \& Bourget 1996, Cummings et al. 1997, Johnson et al. 1997, Schneider et al. 1997). In intertidal habitats, patch and disturbance dynamics result in a positive influence of mussel patch size on species diversity and resilience (Paine \& Levin 1981, Kim \& Dewreede 1996). Topographic heterogeneity increases benthic invertebrate abundance and recruitment with scales from $10^{-3}$ to $10^{-1} \mathrm{~m}$ (Archambault \& Bourget 1996, Lemire \& Bourget 1996) and from $10^{2}$ to $10^{3} \mathrm{~m}$ (Archambault \& Bourget 1996, Blanchard \& Bourget 1999). Scales of topographic heterogeneity between 0.5 and $2 \mathrm{~m}$ also facilitate benthic fish recruitment (Breitburg et al. 1995) and decrease the nearby softbottom species richness (Cusson \& Bourget 1997). Guichard \& Bourget (1998) showed that the presence of natural boulders had a negative effect on Mytilus and Fucus sp. biomass as a function of boulder size. Boulders are more spherical than cylinders. In the earlier study, areas under boulders, and thus current acceleration zones near the edge of boulders, were not sampled, and this may explain the reported inverse influence of topographic scale on Mytilus biomass (Guichard \& Bourget 1998). However, there may be a more complex dependence of scaling rules on external forcing factors. Here we found that the biomass of all numerically dominant invertebrate species (Mytilus, Littorina saxatilis and L. obtusata) was affected by artificial reefs. Reef size had a negative effect on all species, but Mytilus biomass was maximum around large reefs. Flow acceleration on the reef's sides had a positive influence on Mytilus biomass. The overall increase in Mytilus around large reefs was only near the edge of reefs, while there was a decrease in Mytilus biomass and density of large individuals downstream, where flow velocity was lowest. While both substratum temperature and hydrodynamic patterns were influenced by artificial reefs, we found that flow velocity was the dominant factor mediating the scaling of benthic communities to topographic heterogeneity, while substratum temperature was the dominant factor for solitary individuals (Mytilus growth). These alternate trajectories lead to major changes in scaling rules. For Mytilus biomass there was a scale threshold (large reefs) and symmetrically oriented patterns along the main flow orientation. However, the scaling of solitary Mytilus growth with reef size resulted in patterns that were maximum around medium reefs with no scale threshold and oriented patterns.

\section{Conclusion}

Biological scaling rules, changes in biological patterns with topographic scale, depend on observation level, individual versus population, and can have major impacts on pattern formation and population dynamics. Temporal changes in abiotic external forcing, such as increased air temperature, could lead to a switch from hydrodynamics to temperature as the main factor mediating the influence of topographic heterogeneity on benthic communities. Since local scaling rules can influence large-scale population dynamics (Pacala \& Levin 1997), switching local scaling rules and resulting local patterns could impact the largescale dynamics of benthic communities. These results further suggest that the relationship between topographic heterogeneity and benthic communities can take alternate trajectories depending on the dominant mediating physical factors such as hydrodynamics or shading.

Acknowledgements. We acknowledge the help of S. Petijean, F. Comi and T. Debuigne in the field. We also thank M. Fréchette (Institut Maurice-Lamontagne, Fisheries and Oceans Canada) for laboratory facilities while in the field, and G. Daigle for help with statistical analysis. This research was supported by NSERC grants to E.B. and FCAR scholarships to F.G. This is a contribution to the program of GIROQ (Groupe Interuniversitaire de Recherches Océanographique du Québec).

\section{LITERATURE CITED}

Archambault D, Bourget E (1983) Importance du régime de dénudation sur la structure et la succession des communautés intertidales de substrat rocheux en milieu subarctique. Can J Fish Aquat Sci 40:1278-1292

Archambault P, Bourget E (1996) Scales of coastal heterogeneity and benthic intertidal species richness, diversity and abundance. Mar Ecol Prog Ser 136:111-121

Archambault P, Roff JC, Bourget E, Bang B, Ingram GR (1998) Nearshore abundance of zooplankton in relation to shoreline configuration and mechanisms involved. J Plankton Res 20:671-690

August PV (1983) The role of habitat complexity and heterogeneity in structuring tropical mammal communities. Ecology 64:1495-1507

Bartha S, Collins SL, Glenn SM, Kertész M (1995) Fine-scale spatial organization of tallgrass prairie vegetation along a topographic gradient. Folia Geobot Phytotax 30:169-184

Bascompte J, Solé R (1995) Rethinking complexity: modelling spatiotemporal dynamics in ecology. Trends Ecol Evol 10: 361-366

Bergeron P, Bourget E (1986) Shore topography and spatial partitioning of crevice refuges by sessile epibenthos in an ice disturbed environment. Mar Ecol Prog Ser 28:129-145

Blanchard D, Bourget E (1999) Scales of coastal heterogeneity: influence on intertidal community structure. Mar Ecol Prog Ser 179:163-173

Boose ER, Foster DR, Fluet M (1994) Hurricane impacts to tropical and temperate forest landscapes. Ecol Monogr 64: $369-400$ 
Bourget E (1988) Barnacle larval settlement: the perception of cues at different spatial scales. In: Chelazzi G, Vannini M (eds) Behavioral adaptation to intertidal life. Plenum, New York, p 153-172

Breitburg DL, Palmer MA, Loher T (1995) Larval distributions and the spatial patterns of settlement of a oyster reef fish: responses to flow and structure. Mar Ecol Prog Ser 125: 45-60

Butman CA, Fréchette M, Geyer WR, Starczack VR (1994) Flume experiments on food supply to the blue mussel Mytilus edulis L. as a function of boundary-layer flow. Limnol Oceanogr 39:1755-1768

Connell JH (1961) Effects of competition, predation by Thais lapillus and other factors on natural populations of the barnacle Balanus balanoides. Ecol Monogr 31:61-104

Cummings VJ, Schneider DC, Wilkinson MR (1997) Multiscale experimental-analysis of aggregative responses of mobile predators to infaunal prey. J Exp Mar Biol Ecol 216: 211-227

Cusson M, Bourget E (1997) Influence of topographic heterogeneity and spatial scales on the structure of the neighbouring intertidal endobenthic macrofaunal community. Mar Ecol Prog Ser 150:181-193

Denny MW, Shibata MF (1989) Consequences of surf-zone turbulences for settlement and external fertilization. Am Nat 134:859-889

Deutschman DH, Bradshaw GA, Childress WM, Daly K, Grunbaum D, Pascual M, Schumaker NH, Wu J (1993) Mechanisms of patch formation. In: Levin S, Powell T, Steel J (eds) Patch dynamics. Springer, Berlin, p 184-209

Drapeau G (1990) Nearshore sediment dynamics in the St. Lawrence estuary. In: Silverberg N, El-Sabh M (eds) Oceanography of a large-scale estuarine system, the St. Lawrence. Coast Estuar Stud 13:130-154

Fréchette M, Bourget E (1985) Food-limited growth of Mytilus edulis L. in relation to the benthic boundary layer. Can J Fish Aquat Sci 42:1166-1170

Fréchette M, Butman CA, Geyer W (1989) The importance of boundary-layer flows in supplying phytoplankton to the benthic suspension feeder, Mytilus edulis L. Limnol Oceanogr 34:19-36

Garrity SD (1984) Some adaptations of gastropods to physical stress on a tropical rocky shore. Ecology 65:557-574

Gaylord B, Blanchette CA, Denny MW (1994) Mechanical consequences of size in wave-swept algae. Ecol Monogr 64:287-313

Gosselin LA, Bourget E (1989) The performance of an intertidal predator Thais lapillus, in relation to structural heterogeneity. J Anim Ecol 58:287-303

Granger RA (1995) Fluid mechanics. Dover classics of science and mathematics. Dover, New York

Guichard F, Bourget E (1998) Topographic heterogeneity, hydrodynamics, and benthic community structure: a scale-dependent cascade. Mar Ecol Prog Ser 171:59-70

Hadji S, Dhatt G (1997) Asymptotic-Newton method for solving incompressible flows. Int J Numer Method Fluid 25: 861-878

Harvey M, Bourget E, Ingram G (1995) Experimental evidence of passive accumulation of marine bivalve larvae on filamentous epibenthic structure. Limnol Oceanogr 40: 94-104

Helmuth BST (1998) Intertidal mussel microclimates: predicting the body temperature of a sessile invertebrate. Ecol Monogr 68:51-74

Hofer U, Bersier LF, Borcard D (1999) Spatial organization of a herpetofauna on an elevational gradient revealed by null model tests. Ecology 80:976-988
Johnson M, Burrows M, Hartnoll R, Hawkins S (1997) Spatial structure on moderately exposed rocky shores: patch scales and the interactions between limpets and algae. Mar Ecol Prog Ser 160:209-215

Kim JH, Dewreede RE (1996) Effects of size and season of disturbance on algal patch recovery in a rocky intertidal community. Mar Ecol Prog Ser 133:217-228

King AW, Pimm SL (1983) Complexity, diversity and stability: a reconciliation of theoretical and empirical results. Am Nat 122:229-239

Komatsu T, Kawai H (1992) Measurements of time-averaged intensity of water motion with plaster balls. J Oceanogr 48: 353-365

Legendre P, Thrush SF, Cummings VJ, Dayton PK, Grant J, Hewitt JE, Hines AH, McArdle BH, Pridmore RD, Schneider DC, Turner SJ, Whitlatch RB, Wilkinson MR (1997) Spatial structure of bivalves in a sandflat-scale and generating processes. J Exp Mar Biol Ecol 216:99-128

Lemire M, Bourget E (1996) Substratum heterogeneity and complexity influence micro-scale selection of Balanus sp. and Tubularia crocea larvae. Mar Ecol Prog Ser 135: $77-87$

Le Tourneux F, Bourget E (1988) Importance of physical and biological settlement cues used at different spatial scales by the larvae of Semibalanus balanoides. Mar Biol 97: $57-66$

Levin SA, Grenfell B, Hastings A, Perelson AS (1997) Mathematical and computational challenges in population biology and ecosystems science. Science 275:334-343

Lighthill J (1986) An informal introduction to theoretical fluid mechanics. IMA monograph series, Vol 2. Clarendon, Oxford

McCook L, Chapman A (1991) Community succession following massive ice-scour on a exposed rocky shore: effects of Fucus canopy algae and mussels during late succession. J Exp Mar Biol Ecol 154:137-169

McLaughlin JF, Roughgarden J (1992) Predation across spatial scales in heterogeneous environments. Theor Popul Biol 41:277-299

Norton T (1974) The zonation of seaweeds on rocky shores. In: Moore P, Seed R (eds) The ecology of rocky coasts. Hodder \& Stoughton, London, p 7-21

Nowell A, Jumars P (1984) Flow environment of aquatic benthos. Annu Rev Ecol Syst 15:303-328

Okamura B (1986) Group living and the effects of spatial position in aggregation of Mytilus edulis. Oecologia 69: 341-347

Pacala S, Levin S (1997) Biologically generated spatial pattern and the coexistence of competing species. In: Tilman D, Kareiva P (eds) Spatial ecology: the role of space in population dynamics and interspecific interactions. Princeton University Press, Princeton, p 204-232

Paine R, Levin SA (1981) Intertidal landscapes: disturbance and the dynamics of pattern. Ecol Monogr 51:145-178

Pascual M, Caswell H (1997) Environmental heterogeneity and biological pattern in a chaotic predator-prey system. J Theor Biol 185:1-13

Petraitis PS (1987) Factors organizing rocky intertidal communities of New England: herbivory and predation in sheltered bays. J Exp Mar Biol Ecol 109:117-136

Robert JL, Hamedi MH (1995) Introduction des conditions réelles de débit aux limites d'un modèle hydrodynamique. Can J Civil Eng 22:1133-1142

Robert JL, Khelifi M, Ghanmi A (1998) Use of 2D mixing length distribution to correctly predict turbulent flows in irregular domain. Can J Civil Eng 25:232-240

Roughgarden J (1974) Population dynamics in a spatially 
varying environment: how population size tracks spatial variation in carrying capacity. Am Nat 108:649-664

SAS Institute (1988) SAS/STAT user's guide, release 6.03. SAS Institute Inc, Cary, NC

Schneider DC, Walters R, Thrush S, Dayton P (1997) Scale-up of ecological experiments: density variation in the mobile bivalve Macoma liliana. J Exp Mar Biol Ecol 216:129-152

Seed R, Suchanek TH (1992) Population and community ecology of Mytilus. In: Gosling E (ed) The mussel Mytilus: ecology, physiology, genetics and culture. Developments in aquaculture and fisheries science, Vol 25. Elsevier, Amsterdam, p 87-169

Seuront L, Schmitt F, Lagadeuc Y, Schertzer D, Lovejoy S, Frontier S (1996) Multifractal analysis of phytoplankton biomass and temperature in the ocean. Geophys Res Lett 23:3591-3594

Simpson GG (1964) Species diversity of North American recent mammals. Syst Zool 13:57-73

Suchanek T (1985) Mussels and their role in structuring rocky shore communities. In: Moore P, Seed R (eds) The ecology of rocky coasts. Hodder and Stoughton, London, p 70-96

Svane I, Ompi M (1993) Patch dynamics in beds of the blue mussel Mytilus edulis L.: effects of site, patch size, and position within a patch. Ophelia 37:187-202

Svane I, Setyobudiandi I (1996) Diversity of associated fauna in beds of the blue mussel Mytilus edulis L.: effects of location, patch size, and position within a patch. Ophelia 45: 39-53

Takaoka S, Sasa K (1996) Landform effects on fire behavior

Editorial responsibility: Otto Kinne (Editor), Oldendorf/Luhe, Germany and postfire regeneration in the mixed forests of northern Japan. Ecol Res 11:339-349

Thompson RC, Wilson BJ, Tobin ML, Hill AS, Hawkins SJ (1996) Biologically generated habitat provision and diversity of rocky shore organisms at a hierarchy of spatial scales. J Exp Mar Biol Ecol 202:73-84

Tilman D, Kareiva P (1997) Spatial ecology: the role of space in population dynamics and interspecific interactions. Monographs in population biology, Vol 30. Princeton University Press, Princeton

Tilman D, Pacala S (1993) The maintenance of species richness in plant communities. In: Ricklefs R, Schluter D (eds) Species diversity in ecological communities. University of Chicago Press, Chicago, p 13-25

Tritton D (1988) Physical fluid dynamics. Clarendon, Oxford

Tsuchiya M, Nishihira M (1995) Islands of Mytilus as a habitat for small intertidal animals: effect of island size on community structure. Mar Ecol Prog Ser 25:71-81

Wethey DS, Walters LJ (1986) Quantifying spatial patterns of overgrowth in epibenthic communities. Mar Ecol Prog Ser 29:271-278

Wiens J (1989) Spatial scaling in ecology. Funct Ecol 3: 385-397

Wildish D, Kristmanson D, Hoar R, DeCoste A, McCormick S, White A (1987) Giant scallop feeding and growth response to flow. J Exp Mar Biol Ecol 113:207-220

Wolanski E, Hammer WM (1988) Topographically controlled fronts in the ocean and their biological influence. Science 241:177-181

Submitted: August 31, 1999; Accepted: February 27, 2001 Proofs received from author(s): July 10, 2001 